Artigo

\title{
Reciclagem de Precipitação e Desflorestamento na Amazônia: Um Estudo de Modelagem Numérica
}

\author{
Luiz Gustavo Teixeira da Silveira ${ }^{1}$, Francis Wagner Silva Correia ${ }^{1}$, Sin Chan $\mathrm{Chou}^{2}$, \\ André Lyra ${ }^{2}$, Weslley Brito Gomes ${ }^{3}$, Leonardo Vergasta ${ }^{3}$, Paulo Ricardo Teixeira Silva ${ }^{1}$ \\ ${ }^{1}$ Universidade do Estado do Amazonas, Manaus, AM, Brasil. \\ ${ }^{2}$ Centro de Previsão de Tempo e Estudos Climáticos, Instituto Nacional de Pesquisas Espaciais, \\ Cachoeira Paulista, SP, Brasil.
}

Recebido em 16 de Maio de 2016 - Aceito em 16 de Maio de 2017

\begin{abstract}
Resumo
O modelo regional ETA do Instituto Nacional de Pesquisas Espaciais (INPE) foi utilizado para avaliar o papel das mudanças nos usos e cobertura da terra na reciclagem de precipitação na bacia amazônica através de cenários de desflorestamento referente ao estado atual e projeções futuras. A reciclagem de precipitação aumentou de sudeste para norte-noroeste sobre a bacia, com valores variando entre $20 \%$ a $40 \%$, estando diretamente relacionado à intensificação no transporte de umidade no sentido leste-oeste. As mudanças significativas na reciclagem ocorreram nos cenários de 2050 e 2100, enquanto que, para a situação atual, as mudanças não foram intensas suficientes para afetar o regime de precipitação na bacia. As reduções na reciclagem de precipitação (9\% e 30\% para os cenários de 2050 e 2100 , respectivamente) foram explicadas pela redução na evapotranspiração e aumento no transporte de umidade; entretanto, a redução na evapotranspiração teve papel preponderante. A redução na precipitação total foi determinada pela redução da precipitação advectada (68\%) e local (32\%). Se as atividades antropogênicas não permitirem que haja a regeneração ambiental, o equilíbrio clima-vegetação será afetado, conduzindo a uma condição mais quente e seca, que por sua vez, implicará em graves consequências para os ecossistemas da Amazônia.
\end{abstract}

Palavras-chave: Amazônia, reciclagem de precipitação, transporte de umidade, balanço de água, desflorestamento.

\section{Precipitation Recycling and Deforestation in the Amazon: A Numerical Modeling Study}

\begin{abstract}
The regional model ETA of National Institute for Space Research (INPE) was used to assess the role of changes in the use and land cover in the recycling of rainfall in the Amazon basin through deforestation scenarios for the current state and future projections. Precipitation recycling southeast of increased north-northwest of the basin, with values ranging from $20 \%$ to $40 \%$, is directly related to the intensification of the moisture transport in the east-west direction. Significant changes in recycling occurred in the scenarios 2050 and 2100, while for the current situation, the changes were not intense enough to affect the rainfall regime in the basin. Reductions in recycling precipitation $(9 \%$ and $30 \%$ for the scenarios 2050 and 2100, respectively) were explained by reduction in the evapotranspiration and increased moisture transport; however, the reduction in evapotranspiration had a preponderant role. The reduction in the total precipitation was determined by reduction of advected precipitation (68\%) and local (32\%). If anthropogenic activities do not allow there environmental regeneration, climate-vegetation balance will be affected, leading to a warmer and dry condition, which in turn, will result in serious consequences for the Amazon ecosystems.
\end{abstract}

Keywords: Amazon, precipitation recycling, moisture transport, water budget, deforestation.

Autor de correspondência: Francis Wagner Silva Correia, francis.wagner70@gmail.com. 


\section{Introdução}

A Amazônia é a maior extensão contínua de floresta tropical úmida do planeta com uma área total de aproximadamente 6,3 milhões de $\mathrm{km}^{2}$, que representa $56 \%$ das florestas tropicais da Terra, desempenhando papel importante nas trocas de energia, umidade e massa entre a superfície continental e a atmosfera, e fornecendo serviços ambientais fundamentais para o clima em escalas regional e global, tais como: manutenção da biodiversidade, o armazenamento e absorção do excesso de carbono da atmosfera e o transporte de gases traço, aerossóis e vapor d'água para outras regiões e, principalmente, a reciclagem de precipitação, de grande importância para manutenção dos seus ecossistemas (Fearnside, 2005). Devido a sua grande extensão, a floresta amazônica desempenha papel importante nos balanços globais de carbono e água entre a superfície e a atmosfera (Grace et al., 1996; Malhi et al., 1998; Cox et al., 2004; Marengo, 2006a,b; Nobre et al., 2009). No contexto da circulação regional, a floresta amazônica constitui-se uma importante fonte de umidade para o Centro, Sudeste e Sul do Brasil, assim como para o norte da Argentina, incluindo a bacia do Prata, contribuindo para o regime de precipitação nessas regiões (Vera et al., 2006; Arraut e Satyamurty, 2009).

Entretanto, a floresta amazônica é sensível às variabilidades e mudanças no sistema climático, devido tanto às variações naturais, inerentes ao próprio sistema (interações não lineares), quanto às antropogênicas, tais como: o aumento na concentração dos gases do efeito estufa (GEE) na atmosfera e as mudanças no uso da terra, por exemplo: desflorestamento, atividades agrícolas e urbanização (Cox et al., 2004; Correia et al., 2007; Von Randow et al., 2013; Zhang et al., 2015; Marengo e Espinoza, 2015). Embora esses diferentes estudos sobre as mudanças nos usos e cobertura da terra na Amazônia tenham produzido conhecimentos acerca da interação entre os processos de superfície e o ciclo hidrológico na região, os efeitos dessas mudanças no mecanismo de reciclagem de precipitação ainda não são completamente compreendidos necessitando, dessa forma, serem investigados.

Segundo levantamento realizado pelo Instituto de Pesquisas Espaciais (INPE), a taxa de desflorestamento na Amazônia foi aproximadamente $5.500 \mathrm{~km}^{2}$ no período de 2014 a 2015 , com um aumento de $14 \%$ em relação ao período anterior (2013-2014), sendo a região do Estado do Mato Grosso a área mais afetada. Considerando a série histórica do monitoramento o desflorestamento total na Amazônia foi de aproximadamente $413.506 \mathrm{~km}^{2}$, aproximadamente $15 \%$ do total da floresta amazônica brasileira, com uma média anual de $14.800 \mathrm{~km}^{2}$ entre os anos de 1988 a 2015 (INPE, 2015).

A avaliação dos impactos do desflorestamento no clima tem sido realizada em diferentes estudos propostos na literatura (Voldoire e Royer, 2004; Correia et al., 2007; Nobre et al., 2009; Rocha e Correia, 2015). De forma geral, os estudos mostram que o desflorestamento de grande escala na Amazônia conduz a impactos significativos nos balanços de radiação, de energia e de água, com aumento na temperatura da superfície $\left(1-3{ }^{\circ} \mathrm{C}\right)$, redução na evapotranspiração (- $40 \%)$ e redução na precipitação total da ordem de $30 \%$. Diante dos possíveis impactos regionais decorrentes das alterações na cobertura e usos da terra é de fundamental importância avaliar os efeitos dessas alterações não somente nos componentes do balanço de água, mas no mecanismo de reciclagem de precipitação, uma vez que, representa um forte indicador da importância dos processos de superfície e do clima no ciclo hidrológico, assim como, da sensibilidade climática relacionada às alterações nesses processos. Desta forma, o objetivo desse trabalho foi realizar um estudo de modelagem numérica para avaliar o papel das mudanças nos usos e cobertura da terra (desflorestamentos) na reciclagem de precipitação na bacia amazônica referentes ao estado atual e projeções para situações futuras.

\section{Material e Métodos}

\subsection{Modelo de reciclagem de precipitação}

Utilizou-se nesse estudo o modelo de reciclagem fundamentado no balanço de umidade da atmosfera proposto por Brubaker et al. (1993) e Trenberth (1999). No modelo a reciclagem de precipitação é estimada em função da evapotranspiração local $(E)$, da precipitação total $(P)$, dos fluxos de vapor d'água que entram $\left(F_{\text {in }}\right)$ e saem $\left(F_{\text {out }}\right)$ em uma determinada região e do comprimento de escala $L$ (Fig. 1). Considerando esses parâmetros, o fluxo de saída na região é dado por:

$$
F_{\text {out }}=F_{\text {in }}+(E-P) L
$$

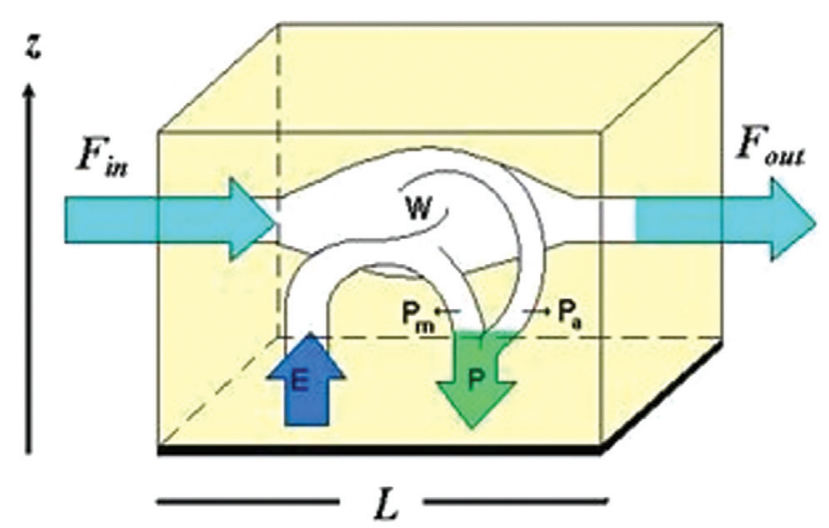

Figura 1 - Modelo conceitual de reciclagem de precipitação. Os termos $P_{m}$ e $P_{a}$ referem-se às taxas de precipitação provenientes da evapotranspiração e do vapor d'água advectados para a região, respectivamente; $F_{\text {in }} \mathrm{e}$ $F_{\text {out }}$ são os fluxos de vapor dágua que entra e sai da região considerada, respectivamente; $E$ é a taxa de evapotranspiração e $W$ é o armazenamento de água na atmosfera (água precipitável). Fonte: Adaptado de Brubaker et al. (1993). 
onde o fluxo horizontal médio do vapor d'água na área é definido como:

$$
F=0,5\left(F_{\text {in }}+F_{\text {out }}\right)=F_{\text {in }}+0,5(E-P) L
$$

A precipitação total $(P)$ na região é particionada em precipitação de origem local $\left(P_{l}\right)$ e precipitação de origem advectada $\left(P_{a}\right)$, dada por:

$$
P=P_{l}+P_{a}
$$

Dessa forma, o fluxo horizontal médio proveniente da umidade advectada para a região é dado por:

$$
F_{\text {in }}-0,5 P_{a} L
$$

e o fluxo horizontal médio decorrente da evapotranspiração local é dado por:

$$
0,5\left(E-P_{l}\right) L
$$

Assumindo que a atmosfera é bem misturada, de maneira que a razão da precipitação proveniente da advecção vs. a decorrente da evapotranspiração é proporcional à razão entre o fluxo de umidade advectado e o evapotranspirado, pode-se determinar que:

$$
\frac{P_{a}}{P_{l}}=\frac{F_{i n}-0,5 P_{a} L}{0,5\left(E-P_{l}\right) L}
$$

Assim, a reciclagem de precipitação $(\beta)$ pode ser determinada por:

$$
\beta=\frac{P_{l}}{P}=\frac{E L}{E L+2 F_{\text {in }}}
$$

Utilizando a Eq. (2), a reciclagem de precipitação ( $\beta$ ) pode ser reescrita da seguinte forma:

$$
\beta=\frac{E L}{E L+2 F}
$$

onde $F$ é o fluxo médio sobre a região. Portanto, o método pressupõe que a atmosfera é bem misturada e a mudança no armazenamento de umidade na atmosfera é desprezível em comparação aos outros termos. Na estimativa de reciclagem para a bacia amazônica, Trenberth (1999) recomenda a utilização do comprimento de escala de $L=2.750 \mathrm{~km}$. A evapotranspiração, a precipitação, e o transporte de umidade foram obtidos a partir das integrações numéricas do modelo de área limitada ETA do CPTEC/INPE.

\subsection{Modelo regional ETA}

O ETA é um modelo atmosférico de área limitada (regional) desenvolvida pela Universidade de Belgrado em conjunto com o Instituto de Hidrometeorologiada Iugoslávia (Mesinger et al., 1988; Black, 1994) e aprimorado por pesquisadores do Centro de Previsão de Tempo e Estudos Climáticos - Instituto Nacional de Pesquisas Espaciais Climáticos (CPTEC/INPE) (Chou et al., 2005 e 2012). Por ser um modelo regional consegue representar melhor os fenômenos de mesoescala, tais como: sistemas frontais, orografia, brisa marítima, tempestades severas e outros sistemas de mesoescala. O ETA é um modelo de ponto de grade baseado na coordenada vertical $(\eta)$ definida por:

$$
\eta=\left[\frac{\left(p-p_{t}\right)}{p_{s f c}-p_{t}}\right] \times\left[\frac{\left(p_{r e f}\left(Z_{s f c}\right)-p_{t}\right)}{\left(p_{\text {ref }}(0)-p_{t}\right)}\right]
$$

onde $p$ é a pressão atmosférica, $Z$ é a altitude, $t, s f c$ e $r e f$ referem-se ao topo da atmosfera, à superfície, e o nível de referência em relação ao nível do mar, respectivamente. As parametrizações incluídas no modelo e que foram utilizadas nesse estudo são: esquema de difusão turbulenta na Camada Limite Planetária (CLP) descrito por MellorYamada (Mellor e Yamada, 1974); esquema de radiação de ondas curta e longa segundo (Fels e Schwarztkof, 1975) e (Lacis e Hansen, 1974), respectivamente; os esquemas de convecção proposto por Betts-Miller (Betts e Miller, 1986), e microfísica de nuvem, descrito em Zhao et al. (1997); os processos de superfície são parametrizados de acordo com o esquema NOAH (Ek et al., 2003), que contém 4 camadas de solo para a temperatura e umidade, assim como distingue 12 tipos de vegetação e 7 tipos de textura de solo. A temperatura da superfície do mar (TSM) foi derivada de médias mensais (climatologia) das reanálises do ERAInterim (Dee et al., 2011). O modelo atualizou diariamente a TSM através de interpolação linear.

\subsection{Cenários de cobertura e usos da terra}

Utilizaram-se três cenários de desflorestamento da Amazônia: a) mapa de cobertura vegetal referente ao ano de 2010 , b) cenário projetado para o ano de 2050 e c) cenário projetado para o ano de 2100 (Fig. 2). Para o ano de 2010 considerou-se o mapa de vegetação elaborado pelo Projeto ProVeg (Sestini et al., 2002) gerado a partir de dados do Projeto RADAMBRASIL, que inclui 26 cartas na escala 1:1.000.000 e, ainda, o mapa de vegetação para todo o Brasil na escala de 1:5.000.000 gerado pelo Instituto Brasileiro de Geografia e Estatística, disponíveis em formato digital. Dados do Projeto de Estimativa do Desflorestamento Bruto da Amazônia - PRODES-DIGITAL (INPE, 2015) foram utilizados para incluir as alterações decorrentes da ação antropogênica (desflorestamento) que vem ocorrendo na região amazônica. Considerou-se o mapeamento do desflorestamento do ano base de 2010. A cobertura vegetal pastagem degradada representa o desflorestamento na bacia amazônica. As projeções futuras referentes aos anos de 2050 e 2100 foram elaboradas a partir do modelo de dinâmica da paisagem DINAMICA (Soares-Filho et al., 2004). DINÂMICA é um modelo de simulação espacial do tipo autômato celular que usa como entrada um conjunto de informações: mapas de uso e cobertura do solo obtido a partir da classificação de imagens de satélites, mapas de tempo de permanência de cada célula no seu estado atual, e um conjunto de variáveis carto- 

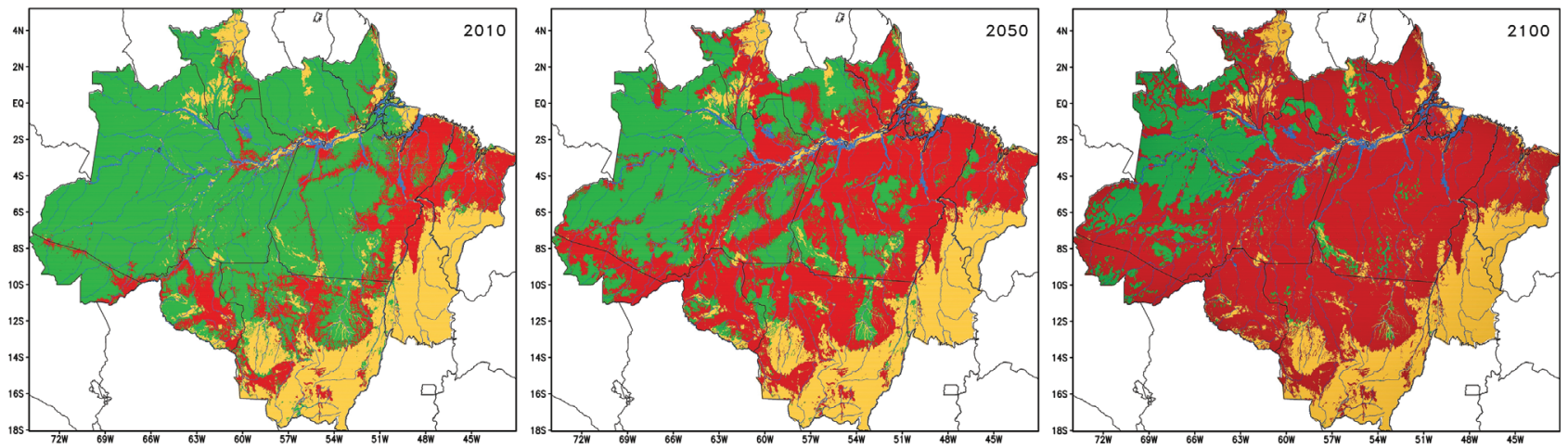

Figura 2 - Cenários de cobertura vegetal utilizados nas simulações com o modelo regional ETA. (a) Mapa de vegetação elaborado pelo Projeto ProVeg com áreas desflorestadas (ano base 2010); (b) Cenário projetado para o ano de 2050e c) Cenário projetado para o ano de 2100 . Ambos cenários elaborados pelo modelo DINÂMICA. Resolução: 1x1 km. Cores: Verde(floresta), Amarelo (Cerrado), Azul (Agua) e Vermelho (Pastagem degradada).

gráficas, que se dividem em dois tipos: estáticas e dinâmicas, sendo as últimas recalculadas em cada iteração do programa. As variáveis cartográficas, por exemplo, solo, vegetação, distância às estradas, altitude, declividade, etc, são combinadas, através da definição de seus pesos de evidência, para gerar os mapas de probabilidades de transição. Após cada iteração, o modelo DINÂMICA produz um novo mapa de paisagem, os mapas de probabilidades de transição e mapas de variáveis dinâmicas. Seu modelo de transição está acoplado a um modelo construtor de estradas, que passa ao programa mapas dinâmicos da rede viária, e a um gerador de cenários, que produz matrizes de transição dinâmicas e as passa ao DINÂMICA, usando-se de sua ligação com o software de modelagem. Diferente dos cenários de cobertura vegetal usados no presente estudo, Oyama e Nobre (2003) e Salazar et al. (2007) obtiveram outras distribuições de vegetação na América do Sul produzidas a partir condições de equilíbrio para o clima presente geradas por modelo de circulação geral da atmosfera (MCGA) e tambem para condições de clima futuro de diferentes cenários de emissões, respectivamente. As propriedades físicas e fisiológicas da vegetação e solo para os principais biomas na Amazônia Legal são apresentadas na Tabela 1.

\subsection{Estratégia de simulação numérica}

Neste estudo foram realizados quatro experimentos numéricos, denominados: CNTRL, C2010, C2050, C2100. No experimento CNTRL utilizou-se o mapa de cobertura vegetal de 2010 sem o desflorestamento. No experimento C2010 utilizou-se a representação da vegetação na região da Amazônia Legal considerando dados de desflorestamento para o ano base de 2010. Nos experimentos 2050 e 2100, utilizaram-se os cenários de desflorestamento da Amazônia Legal projetados para os anos de 2050 e 2100, respectivamente; ambos elaborados pelo modelo de dinâmica de vegetação. Cada experimento consistiu de uma integração contínua de 20 anos, inicializada às $00 \mathrm{~h}$ (TMG Tempo Médio de Greenwith) de 01 de novembro de 1989, considerando spin-up de um ano. As condições iniciais e de contorno da atmosfera foram provenientes das reanálises do ERA-Interim, a mais recente base de dados produzida pelo European Centre for Medium-Range Weather Forecasts - ECMWF (Dee et al., 2011). As reanálises na resolução de $1,0^{\circ} \times 1,0^{\circ}$ para o domínio de $57^{\circ} \mathrm{S}-79,5^{\circ} \mathrm{N} ;-180$ W-180 E, que abrange todos os continentes, exceto a Antártica, estão disponíveis para acesso em:

Tabela 1 - Parâmetros biofísicos utilizados de acordo com o tipo de vegetação.

\begin{tabular}{lccc}
\hline Parâmetros & Floresta & Pastagem & Cerrado \\
\hline Albedo & $0,13^{(1)}$ & $0,18^{(1)}$ & $0,18^{(2)}$ \\
Emissividade & 0,95 & 0,96 & 0,97 \\
Índice de área foliar (IAF) & $5,2^{(1)}$ & $2,7^{(1)}$ & $1,0^{(2)}$ \\
Fração de cobertura vegetal (Vfrac) & $0,98^{(3)}$ & $0,85^{(3)}$ & 0,50 \\
Variação sazonal do Vfrac & 0,05 & 0,10 & 0,30 \\
Comprimento de rugosidade (m) & $2,35^{(1)}$ & $0,05^{(1)}$ & $1,20^{(2)}$ \\
Deslocamento do plano zero (m) & $28,4^{(1)}$ & $0,3^{(1)}$ & $10,0^{(2)}$ \\
Profundidade das raízes (m) & $4,0^{(1)}$ & 1,0 & 2,0 \\
Condutância estomática (mm s & $0,0010^{(4)}$ & $0,0020^{(4)}$ \\
\hline
\end{tabular}

Os índices referem-se aos seguintes estudos: (1) Wright et al. (1996); (2) Miranda et al. (1996); (3) Silva Dias e Regnier (1996); (4) Freitas (1999). FONTE: Extraído de Gandu et al. (2004). 
http://apps.ecmwf.int/datasets/. O modelo assimilou as reanálises a cada 6 horas de integração, através do processo de downscaling dinâmico. Os valores da temperatura da superfície do mar (TSM) foram fornecidos a partir das médias mensais das reanálises do ERA-Interim (ECMWF). A condição inicial da umidade do solo e o albedo da superfície tambem foram obtidos a partir da climatologia das reanálises do ECMWF referente ao primeiro mês de integração e da climatologia sazonal, respectivamente (Dee et al., 2011). Para esse estudo, o modelo ETA foi configurado com uma resolução horizontal de $40 \mathrm{~km}, 38$ camadas na vertical, passo de tempo de 90 segundos e domínio espacial de 15 N-50 S e 25 W-90 W. Durante as integrações numéricas, a concentração de $\mathrm{CO}_{2}$ no modelo ETA foi mantida constante no valor de 369 ppmv. Manteve-se constante o $\mathrm{CO}_{2}$ nas integrações numéricas pelo fato do interesse concentrar-se unicamente nas mudanças decorrentes do uso e cobertura da terra.

\section{Resultados e Discussão}

\subsection{Validação do modelo regional}

Avaliou-se o desempenho do modelo regional ETA na representação da precipitação sobre a América do Sul utilizando dados para o período de janeiro de 1990 a dezembro de 2010 do CRU - Climate Research Unit (New et al., 2000), CMAP - Merged Analysis of Precipitaion (Xie e Arkin, 1997), GPCP - Global Precipitation Climatology Project (Xie et al., 2003), GPCC - Global Precipitation Climatology Centre (Beck et al., 2005) e MERGE (Vila et al., 2009). A distribuição de precipitação nas estações seca e úmida da bacia amazônica é bem representada pelo modelo apresentando maiores valores durante o trimestre Fevereiro-Março-Abril (FMA), estando associado, principalmente, a atuação da Zona de Convergência do Atlântico Sul ZCAS e a Zona de Convêrgencia Intertropical - ITCZ (Fig. 3); e também valores baixos de precipitação na região central e sudeste do Brasil durante o trimestre Julho-Agosto-Setembro (JAS). Entretanto o modelo superestima no extremo noroeste do continente e sobre a Cordilheira dos Andes, mostrando a presença de erros sistemáticos na precipitação devido ao efeito topográfico. No período úmido a banda de precipitação que se estende desde o extremo norte do continente até a região sudeste foi observada tanto nas estimativas de precipitação quanto nos valores simulados. Essa linha de máxima precipitação é decorrente da atuação das ZCAS nesse período, estando associada à convergência de umidade em baixos níveis, sendo intensificado pelos sistemas frontais que organizam a convecção nas porcões sul e cental da bacia amazônica. No trimestre JAS, a maior quantidade de precipitação sobre o continente ocorre na porção norte da América do Sul, litoral leste do Nordeste e sul do Brasil, como observado tanto nos dados de precipitação como na simulação climática.

\subsection{Mudanças regionais}

\subsubsection{Temperatura do ar próximo a superfície $(2 \mathrm{~m})$}

a) Período Úmido

No período úmido observa-se pouca variação espacial e sazonal na temperatura do ar na bacia amazônica decorrente da intensa disponibilidade de energia solar durante o ciclo anual na região. $\mathrm{Na}$ média a temperatura variou entre $24{ }^{\circ} \mathrm{C}$ a $26{ }^{\circ} \mathrm{C}$ sendo influenciada principalmente pela nebulosidade nesse período. A temperatura do ar apresentou aumento em todos os cenários de desflorestamento com valores médios mais intensos nos cenários de 2050 e 2100 (Fig. 4). Os valores variaram entre $1,2^{\circ} \mathrm{C}$, $2,8{ }^{\circ} \mathrm{C}$ e $4,2{ }^{\circ} \mathrm{C}$ para os cenários 2010,2050 e 2100 , respectivamente. $\mathrm{O}$ aquecimento sobre a região desflorestada é decorrente da redução na evapotranspiração e na redução do comprimento de rugosidade, uma vez que, a rugosidade da superfície tem papel fundamental na modulação dos fluxos turbulentos de calor e de umidade entre o continente e a atmosfera. Os padrões espaciais de redução na evapotranspiração observados na Fig. 5 é bem semelhante aos padrões de aumento na temperatura do ar sobre a área desflorestada (Fig. 4). A redução do comprimento de rugosidade (de 2,55 $\mathrm{m}$ na floresta para $0,02 \mathrm{~m}$ na pastagem degradada) reduziu a eficiência da transferência turbulenta de energia na superfície; assim sendo, um valor mais alto de temperatura é necessário para remover o excesso de energia da superfície. Além disso, o menor índice de área foliar (de 5,2 na floresta para 2,7 na pastagem degradada) e a reduzida capacidade de armazenar umidade do solo na pastagem degradada têm o efeito de reduzir a taxa de transpiração; também na pastagem, menos precipitação é interceptada e reevaporada quando o comprimento de rugosidade é relativamente menor.

\section{b) Período Seco}

Observa-se tambem pouca variação espacial e sazonal na temperatura do ar nesse período na bacia amazônica. $\mathrm{Na}$ média a temperatura variou entre $25^{\circ} \mathrm{C}$ a $27^{\circ} \mathrm{C}$ sobre a bacia com valores mais baixos na porção sul durante $\mathrm{o}$ inverno devido a atuação dos sistemas sinóticos (frentes frias) nessa região. Semelhante a estação úmida a temperatura apresentou aumento em todos os cenários de desflorestamento com valores médios mais intensos nos cenários de 2050 e 2100 (Fig. 4). Os valores variaram entre $1,5^{\circ} \mathrm{C}$, $3,0{ }^{\circ} \mathrm{C}$ e $4,5{ }^{\circ} \mathrm{C}$ para os cenários 2010, 2050 e 2100, respectivamente. $\mathrm{O}$ aquecimento tambem foi decorrente da redução na evapotranspiração e na redução do comprimento de rugosidade. Esse aumento de temperatura foi suficiente para compensar tanto o aumento no fluxo turbulento de calor sensível (não mostrado) quanto à diminuição no calor latente (evapotranspiração) com redução média de $87 \mathrm{~W} \mathrm{~m}^{-2}$ para $32 \mathrm{~W} \mathrm{~m}^{-2}$. Isto mostra que, com o desflorestamento mais energia ficou disponível para aquecer a superfície e a atmosfera do que para a evapotranspiração e, 


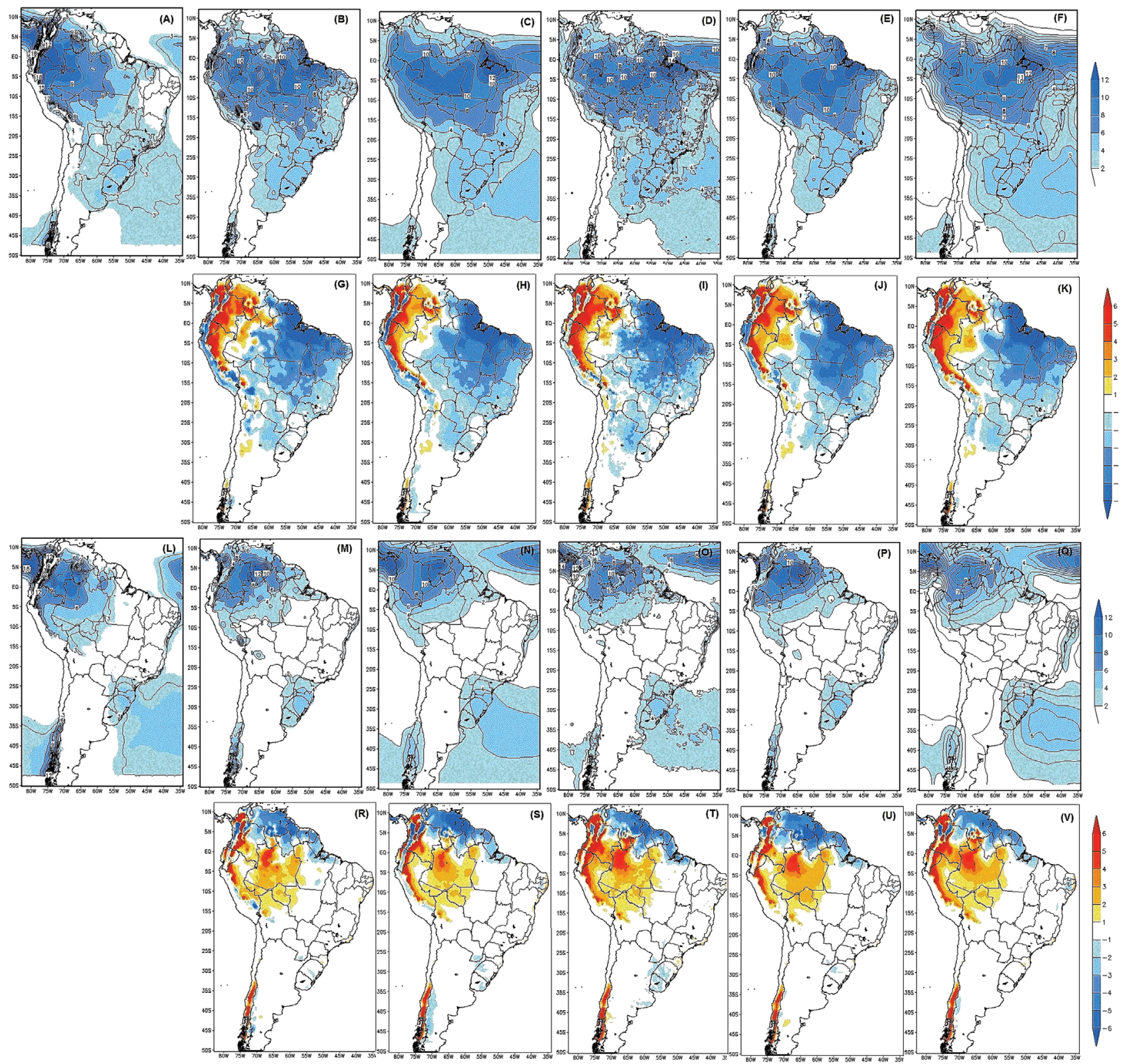

Figura 3 - Distribuição da precipitação $\left(\mathrm{mm} \mathrm{dia}^{-1}\right.$ ) para o período de fevereiro-abril (FMA): (a) Simulada pelo modelo regional ETA; (b) GPCP, (c) GPCC, (d) MERGE, (e) CMAP, (f) (CRU). Bias (mm dia ${ }^{-1}$ ): (g) GPCP-ETA, (h) GPCC-ETA, (i) MERGE-ETA, (j) CMAP-ETA, (k) CRU-ETA. Distribuição da precipitação $\left(\mathrm{mm} \mathrm{dia}^{-1}\right.$ ) para o período de julho-setembro (JAS): (1) Simulada pelo modelo regional ETA; (m) GPCP, (n) GPCC, (o) MERGE, (p) CMAP, (q) (CRU). Bias (mm dia $\left.{ }^{-1}\right)$ : (r) GPCP-ETA, (s) GPCC-ETA, (t) MERGE-ETA, (u) CMAP-ETA, (v) CRU-ETA.

conseqüentemente, conduzir a um aumento na temperatura da superfície sobre a bacia.

\subsubsection{Evapotranspiração, convergência e fluxo de umidade}

A avaliação dos impactos nos componentes do balanço de água faz-se necessário, uma vez que, a reciclagem de precipitação está diretamente associada às variações espaço-temporal desses componentes, conforme modelo proposto por Brubaker et al. (1993) e Tremberth (1999).

a) Período Úmido

Nesse período as reduções mais intensas na evapotranspiração ocorrem nos cenários 2050 e 2100, principal- mente nas porções central-norte da bacia amazônica, com valores variando de $1,0 \mathrm{~mm} \mathrm{dia}^{-1}$ a $1,5 \mathrm{~mm} \mathrm{dia}^{-1}$ para $2050 \mathrm{e}$ 2100, respectivamente (Fig. 5). A redução na evapotranspiração foi devido à diminuição na transpiração e na evaporação da água interceptada pela planta (não mostrado). Além disso, observou-se redução na disponibilidade de umidade do após substituição da floresta por pastagem degradada nos cenários de desflorestamento (não mostrado). O continente sul-americano é caracterizado por uma forte variação anual de precipitação, apresentando grande quantidade de chuvas no verão austral e escassa precipitação durante o inverno. Essa mudança no ciclo das 

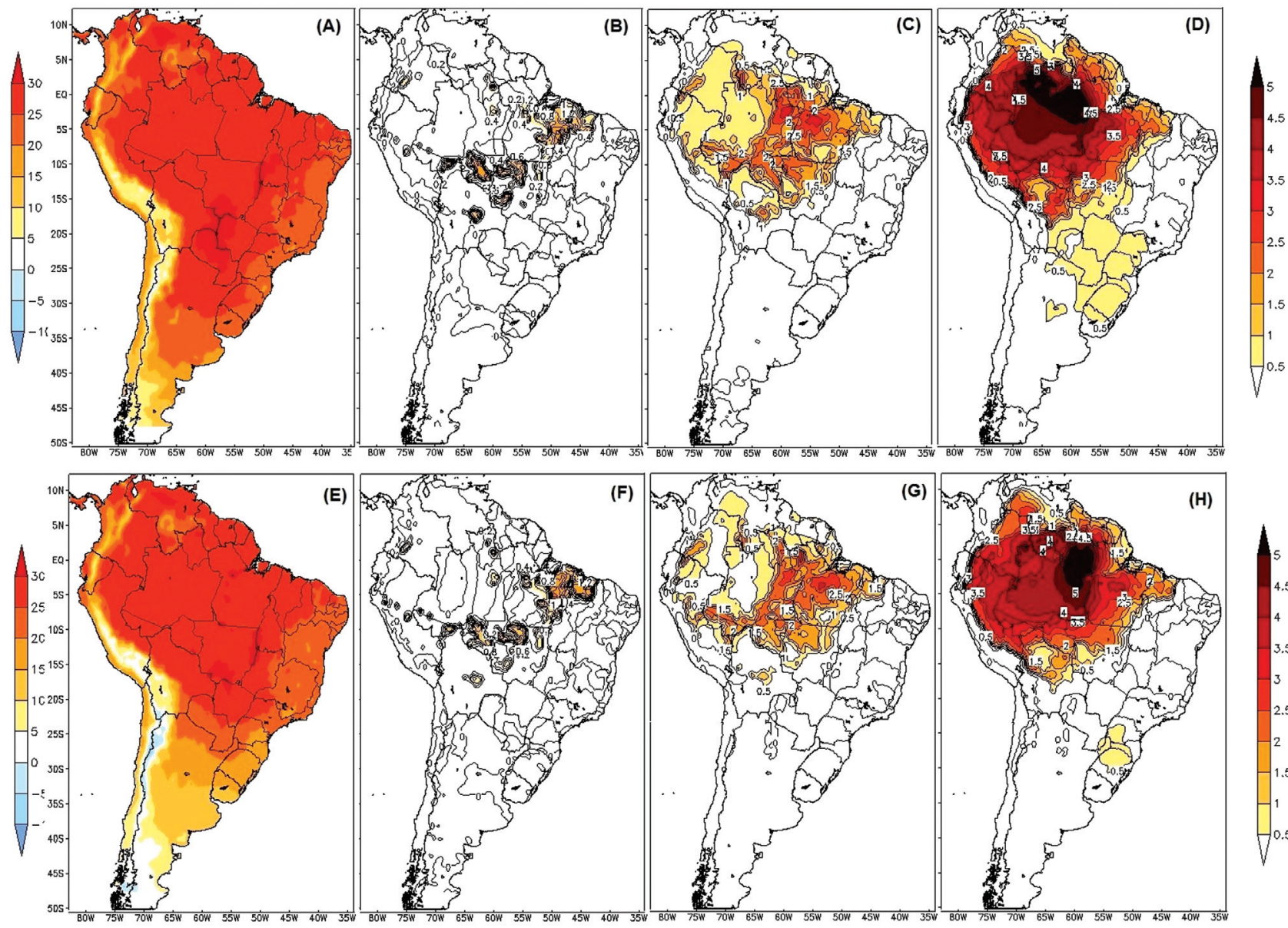

(G)
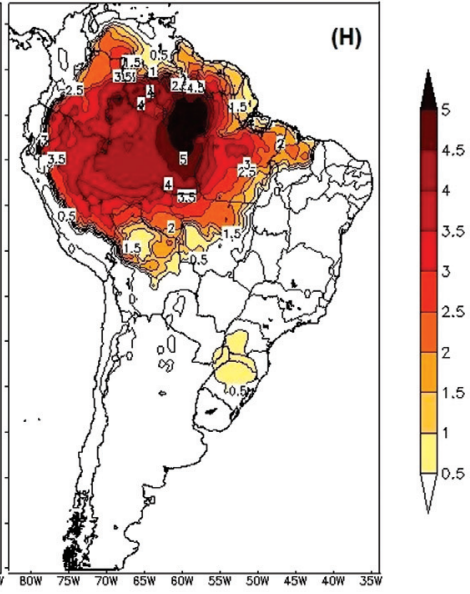

Figura 4 - Impactos na temperatura do ar $\left({ }^{\circ} \mathrm{C}\right)$ decorrentes dos cenários de mudanças nos usos da terra para as estações úmida e seca. Verão: (A) Distribuição da temperatura para o cenário CNTRL; (B) Impactos na temperatura decorrentes do cenário 2010 em relação ao CNTRL; (C) Impactos na temperatura decorrentes do cenário 2050 em relação ao CNTRL; (D) Impactos na temperatura decorrentes do cenário 2100 em relação ao CNTRL. Inverno: (E) Distribuição da temperatura para o cenário CNTRL; (F) Impactos na temperatura decorrentes do cenário 2010 em relação ao CNTRL; (G) Impactos na temperatura decorrentes do cenário 2050 em relação ao CNTRL; (H) Impactos na temperatura decorrentes do cenário 2100 em relação ao CNTRL.

chuvas deve-se à variação anual da circulação atmosférica e da convergência e transporte de vapor d'água sobre o continente. Conforme apresentado nas Figs. 6 e 7, as características da circulação atmosférica sobre a América do Sul tropical e subtropical configura o regime de Monção de Verão da América do Sul - MVAS (Arraut e Satyamurty, 2009), estabelecendo um padrão de intensa convergência de umidade na Amazônia e no Brasil central. O padrão da circulação equatorial são os ventos alísios que transportam umidade do Oceano Atlântico Tropical para a Amazônia, e que estão associados à intensificação da Alta Subtropical do Atlântico Norte durante o verão e outono. Segundo Satyamurty et al. (2013), esse transporte de umidade do Atlântico Equatorial é a principal fonte de umidade para a bacia amazônica e de fundamental importância para o regime de precipitação na região. De forma geral, observou-se que a Amazônia é uma região de sumidouro de umidade, no qual a precipitação é maior que a evapotranspiração e a convergência média de umidade variou en- tre -2 a -6 mm dia ${ }^{-1}$ na estação úmida, corroborando com outros estudos de transporte de umidade (Marengo et al., 2005; Marengo, 2006a). Semelhante a evapotranspiração, nesse período as mudanças mais significativas na convergência de umidade e no transporte de umidade ocorreram nos cenários de 2050 e 2100, enquanto que no ano de 2010 poucas mudanças foram observadas. Nos cenários de 2050 e 2100 observaram-se aumentos e reduções na convergência (e transporte) de umidade na bacia amazônica. Aumento da convergência e transporte de umidade na porção mais ao sul e redução na porção central oeste da bacia foram observados em ambos cenários durante a estação úmida, indicam que o desflorestamento pode produzir uma circulação local (mesoescala) ocasionada por um aquecimento diferencial relacionada à heterogeneidade da superfície, uma vez que, as características térmicas e radiativas da cobertura vegetal foram modificadas. 

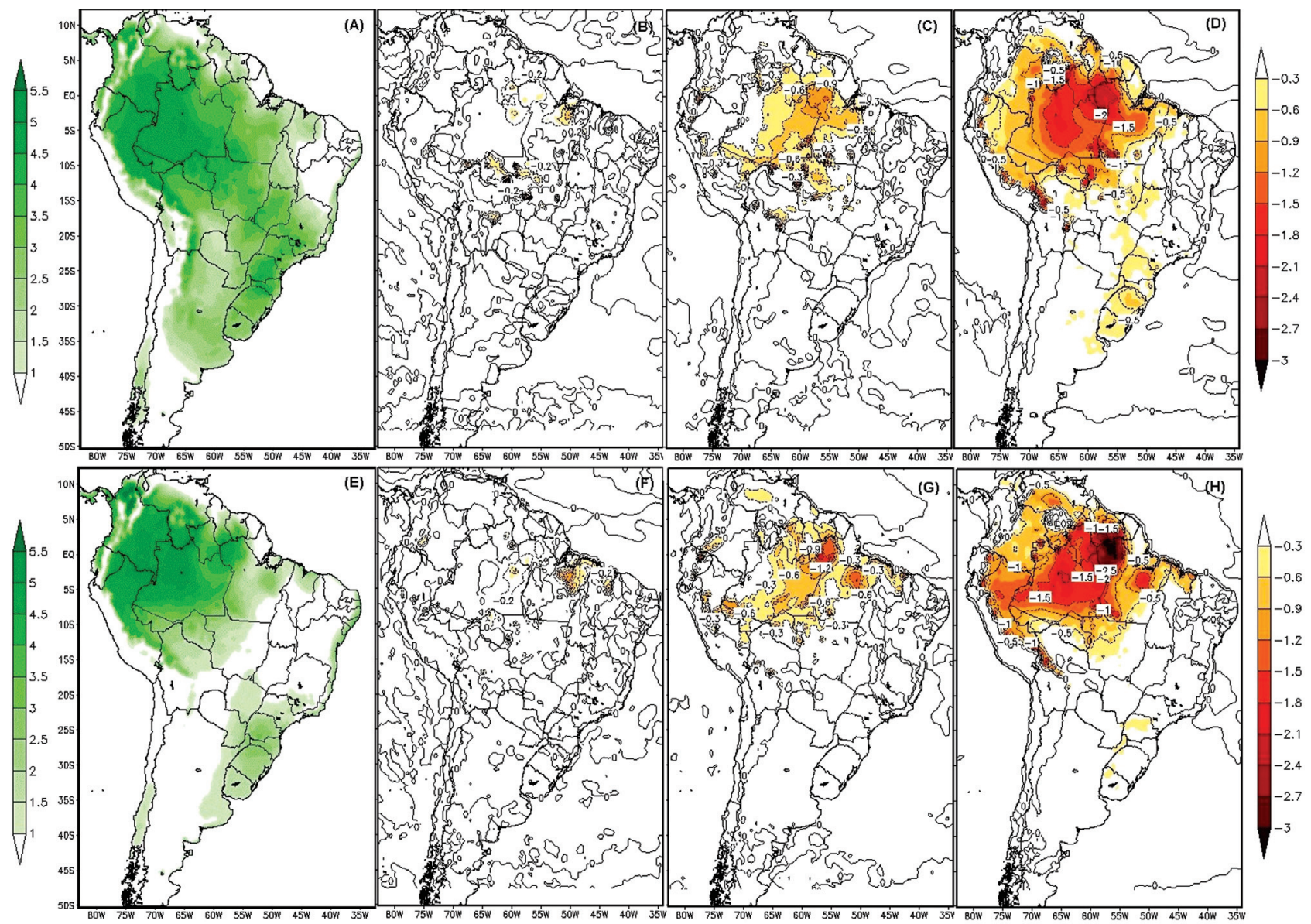

Figura 5 - Impactos na evapotranspiração ( $\mathrm{mm} \mathrm{dia}^{-1}$ ) decorrentes dos cenários de mudanças nos usos da terra para as estações úmida e seca. Verão: (A) Distribuição de evapotranspiração para o cenário CNTRL; (B) Impactos na evapotranspiração decorrentes do cenário 2010 em relação ao CNTRL; (C) Impactos na evapotranspiração decorrentes do cenário 2050 em relação ao CNTRL; (D) Impactos na evapotranspiração decorrentes do cenário 2100 em relação ao CNTRL. Inverno: (E) Distribuição de evapotranspiração para o cenário CNTRL; (F) Impactos na evapotranspiração decorrentes do cenário 2010 em relação ao CNTRL; (G) Impactos na evapotranspiração decorrentes do cenário 2050 em relação ao CNTRL; (H) Impactos na evapotranspiração decorrentes do cenário 2100 em relação ao CNTRL.

\section{b) Período Seco}

Nesse período as reduções mais intensas na evapotranspiração tambem ocorrem nos cenários 2050 e 2100, nas porções central-norte da bacia amazônica, com valores variando de $1,5 \mathrm{~mm} \mathrm{dia}^{-1}$ a $2,5 \mathrm{~mm} \mathrm{dia}^{-1}$ para 2050 e 2100, respectivamente. Semelhante a estação úmida a redução na evapotranspiração foi devido à diminuição na transpiração e na evaporação da água interceptada pela planta. Sazonalmente, as maiores reduções ocorreram na estação seca, sendo a redução na transpiração a principal contribuinte, pois uma menor quantidade de água no solo estava disponível para a planta, devido ao menor comprimento das raízes na pastagem degradada. Assim, as mudanças mais acentuadas na estação seca possivelmente devem estar relacionadas ao estresse de água no solo nesse período, fazendo com que menos água esteja disponível para a transpiração, uma vez que, as raízes são reduzidas na substituição de floresta para pastagem degradada. Resultado semelhange tem sido observado em outros estudos de desflorestamento na Amazônia (Correia et al., 2007; Costa e
Foley, 2000). Nessa estação as mudanças mais significativas na convergência de umidade e no transporte de umidade tambem ocorreram nos cenários de 2050 e 2100 , enquanto que no ano de 2010 poucas mudanças foram observadas. Para situação atual (2010), observou-se pequeno aumento na convergência de umidade no leste do Pará e em Rondônia estando posicionado sobre a região de maior taxa de desflorestamento; entretanto, esse aumento na convergência não foi intenso suficiente para produzir aumento na precipitação sobre a região. Diferente desse resultado, Correia et al. (2007) e Rocha et al. (2015) encontraram aumento da precipitação e convergência de umidade para situação atual de desflorestamento na Amazônia utilizando modelo de circulação de mesoescala.

\subsubsection{Precipitação}

a) Período Úmido

Nesse período não foram observadas mudanças significativas na precipitação para o ano de 2010 , com mudanças mais intensas nos cenários de 2050 e 2100 . Observaram-se 

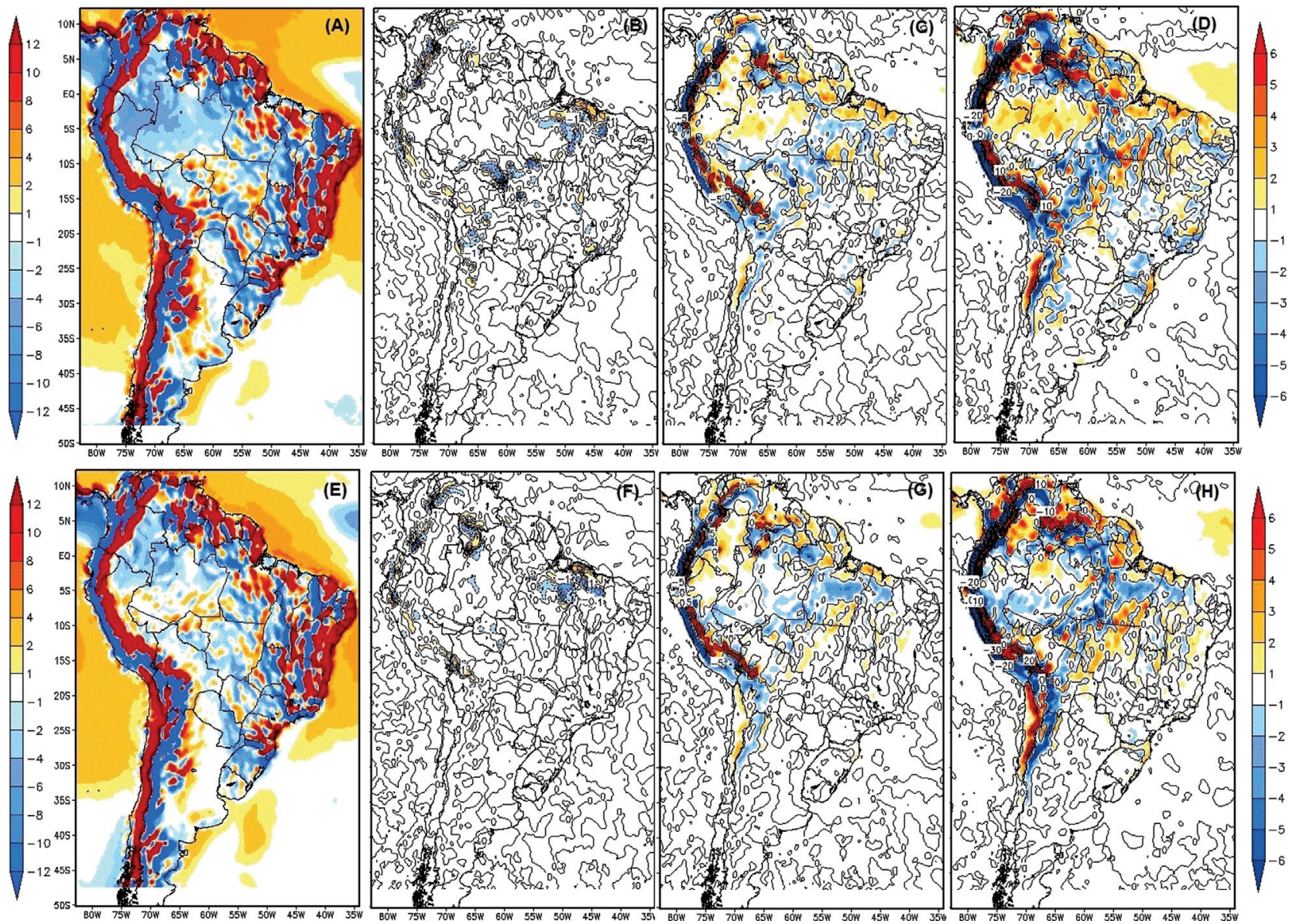

Figura 6 - Impactos na convergência de umidade $\left(\mathrm{mm} \mathrm{dia}^{-1}\right)$ decorrentes dos cenários de mudanças nos usos da terra para as estações úmida e seca. Verão: (A) Distribuição de convergência de umidade para o cenário CNTRL; (B) Impactos na convergência de umidade decorrentes do cenário 2010 em relação ao CNTRL; (C) Impactos na convergência de umidade decorrentes do cenário 2050 em relação ao CNTRL; (D) Impactos na convergência de umidade decorrentes do cenário 2100 em relação ao CNTRL. Inverno: (E) Distribuição de convergência de umidade para o cenário CNTRL; (F) Impactos na convergência de umidade decorrentes do cenário 2010 em relação ao CNTRL; (G) Impactos na convergência de umidade decorrentes do cenário 2050 em relação ao CNTRL; (H) Impactos na convergência de umidade decorrentes do cenário 2100 em relação ao CNTRL.

reduções da ordem de 4 e $5 \mathrm{~mm} \mathrm{dia}^{-1}$ nos cenários 2050 e 2100, respectivamente (Fig. 8). Nesses cenários, as reduções na precipitação concentraram-se na porção centralnorte da bacia amazônica e na região da Zona de Convergência Intertropical (ZCIT), principalmente, com valores mais incensos no cenário de 2100 (Fig. 8). Em ambos cenários, a redução na precipitação foi determinada pela redução na evapotranspiração (13\% - 2050 e $37 \%$ - 2100), uma vez que, na média a convergência de umidade aumentou sobre bacia, com acréscimo de 7\% e 14\% em 2050 e 2100 , respectivamente. Assim, o aumento na convergência de umidade não foi intenso o suficiente para balancear e sobrepujar a redução na evapotranspiração, conduzindo assim a uma redução na precipitação. Esses resultados confirmam o que foi observado em outros estudos propostos na literatura (Correia, 2007; Sampaio et al., 2007; Nobre et al., 2009), isto é, a atmosfera agiu no sentido de minimizar os efeitos da redução na evaporação; contudo nesses cenários, observou-se redução na precipitação em ambas estações, devido à redução na evapo- transpiração. Isso caracteriza a predominância de um mecanismo de retroalimentação (feedback) negativo, no qual, a redução relativa na evapotranspiração foi maior que a redução na precipitação (aumento na convergência de umidade), o que representa um melhor cenário se comparado com mecanismo positivo. Por definição esse feedback é um mecanismo de retroalimentação que promove mudanças na perturbação inicial no sistema, podendo ser positivo ou negativo. No caso desse estudo, observou-se o mecanismo negativo, no qual a mudança na perturbação inicial foi para reduzir os efeitos do desmatamento. Segundo Sud e Fennessy (1984) a redução na evapotranspiração leva a um aumento de temperatura a superfície, gerando assim uma baixa térmica e induzindo uma ascendência, e, conseqüentemente, a um aumento convergência de umidade caracterizando um mecanismo de retroalimentação negativo. $\mathrm{O}$ mecanismo de retroalimentação positivo produz uma instabilidade no sistema, conduzindo a novas degradações da biosfera. De forma contrária, o mecanismo de retroalimentação negativo tem o papel de restaurar a degradação 


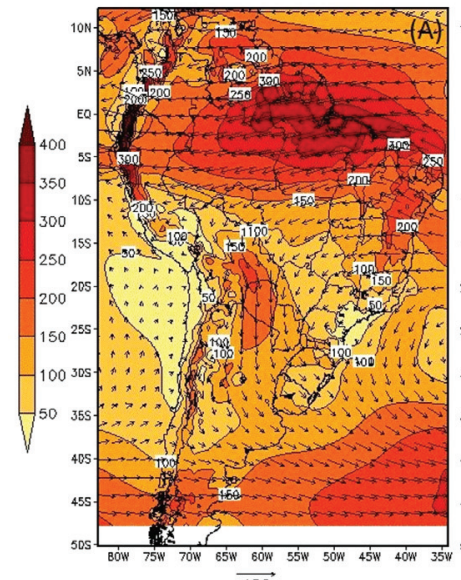

400

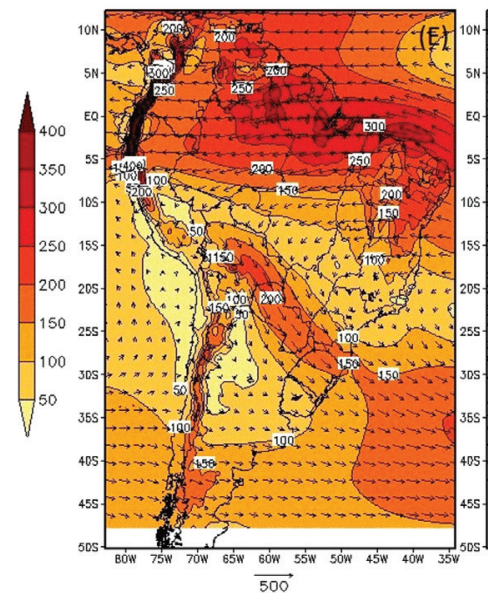

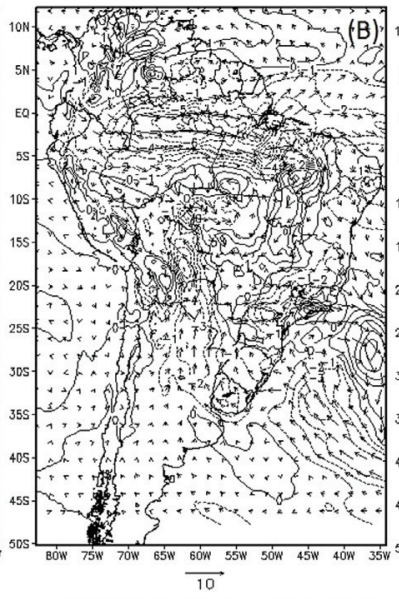
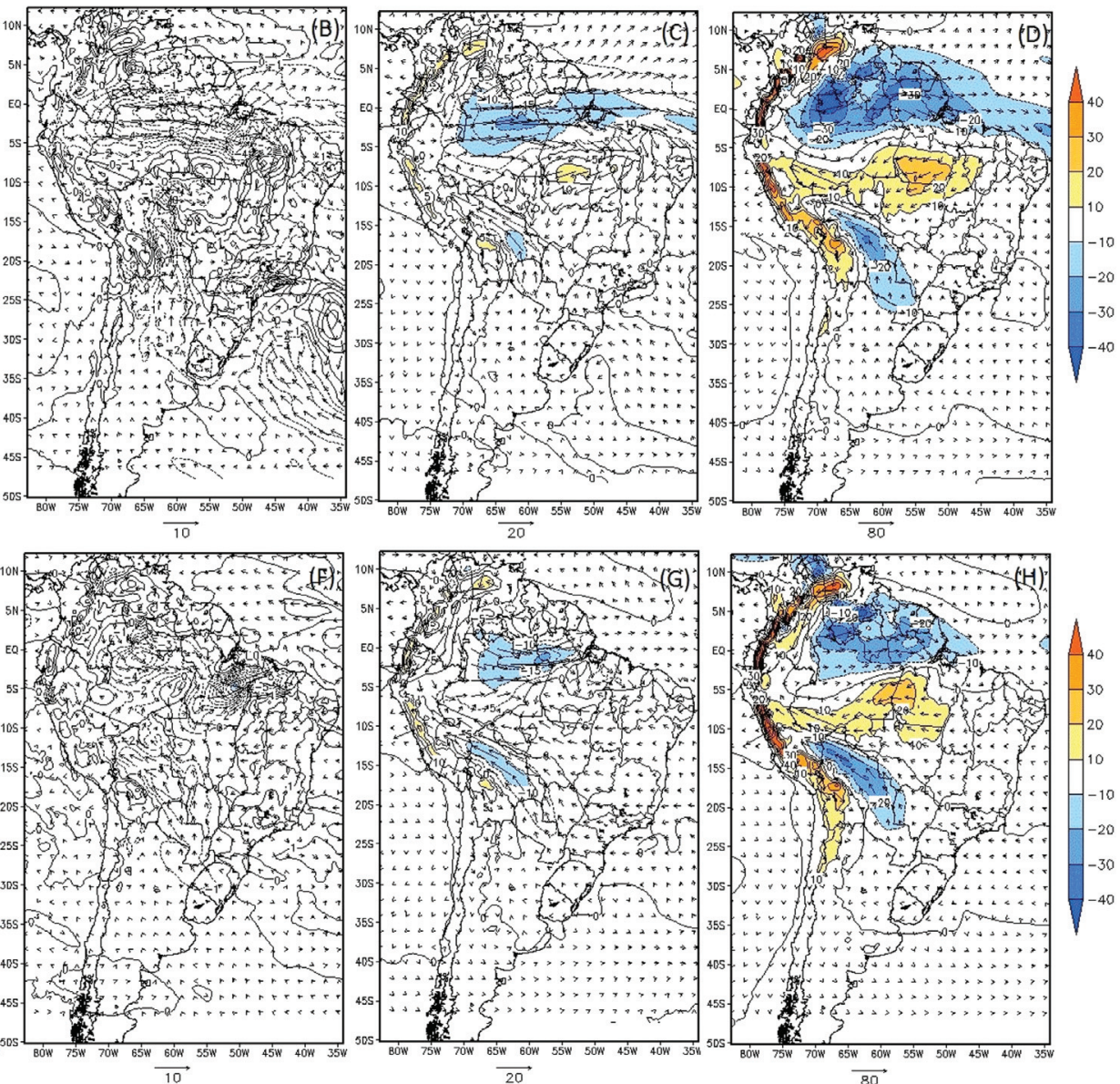

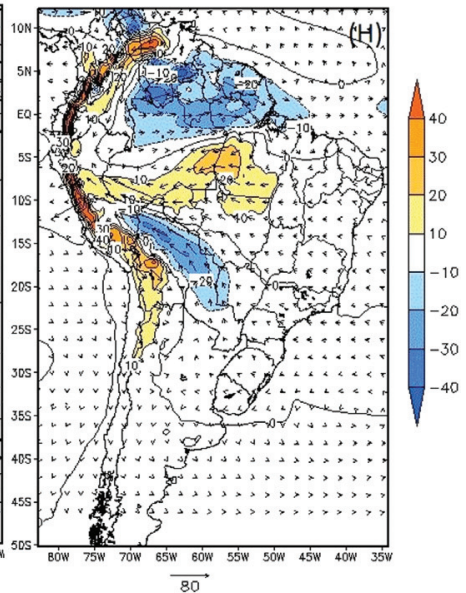

Figura 7 - Impactos no fluxo de umidade $\left(\mathrm{kg} \mathrm{m}^{-1} \mathrm{~s}^{-1}\right)$ decorrentes dos cenários de mudanças nos usos da terra para as estações úmida e seca. Verão: (A) Distribuição do fluxo de umidade para o cenário CNTRL; (B) Impactos no fluxo de umidade decorrente do cenário 2010 em relação ao CNTRL; (C) Impactos no fluxo de umidade decorrente do cenário 2050 em relação ao CNTRL; (D) Impactos no fluxo de umidade decorrentes do cenário 2100 em relação ao CNTRL. Inverno: (E) Distribuição do fluxo de umidade para o cenário CNTRL; (F) Impactos no fluxo de umidade decorrente do cenário 2010 em relação ao CNTRL; (G) Impactos no fluxo de umidade decorrente do cenário 2050 em relação ao CNTRL; (H) Impactos no fluxo de umidade decorrentes do cenário 2100 em relação ao CNTRL.

gerada na cobertura vegetal se a degradação antropogênica for eliminada. Esses resultados mostram que até certo ponto o estado do desflorestamento pode não conduzir a mudanças significativas na precipitação em escala local e regional, entretanto, esse panorama não permanecerá se a degradação antropogênica continuar a expandir como vem acorrendo nas últimas décadas na Amazônia.

\section{b) Período Seco}

Semelhante a estação úmida não foram observadas mudanças significativas na precipitação para o ano de 2010 em ambas as estações, com mudanças mais intensas nos cenários de 2050 e 2100. Observaram-se reduções da ordem de 2 e $3 \mathrm{~mm} \mathrm{dia}^{-1}$ nos cenários 2050 e 2100 , respectivamente. Nesse período as reduções concentraram-se na porção central-norte da bacia amazônica. Na média anual observaram-se reduções $13 \%$ e $35 \%$ nos cenários de 2050 e 2100 , respectivamente (Tabela 2), e sazonalmente, as mudanças mais intensas ocorreram na estação seca no cenário 2100 e na estação úmida em 2050. Assim como na estação úmida, nesse período observou-se a predominância de um mecanismo de retroalimentação negativo, no qual, a redução relativa na evapotranspiração foi maior que a redução na precipitação.

\subsection{Reciclagem de precipitação}

A distribuição espacial e sazonal da reciclagem de precipitação é apresentada na Fig. 9. A reciclagem variou entre $5 \%$ e $50 \%$ sobre o continente com valores extremos na região dos Andes (90\%). Sazonalmente, os valores diminuem do verão para o inverno, sendo sempre mais altos no verão. Os valores mais intensos de reciclagem de precipitação estão localizados nas regiões onde o fluxo de vapor d'água é menos intenso e nas regiões onde o efeito da evapotranspiração é preponderante. Na bacia amazônica, os valores de reciclagem de precipitação tendem a aumentar de norte-noroeste para sudeste, com valores variando entre $20 \%$ (norte) a $40 \%$ (sul); estando diretamente relacionados à intensidade do transporte de umidade, que 

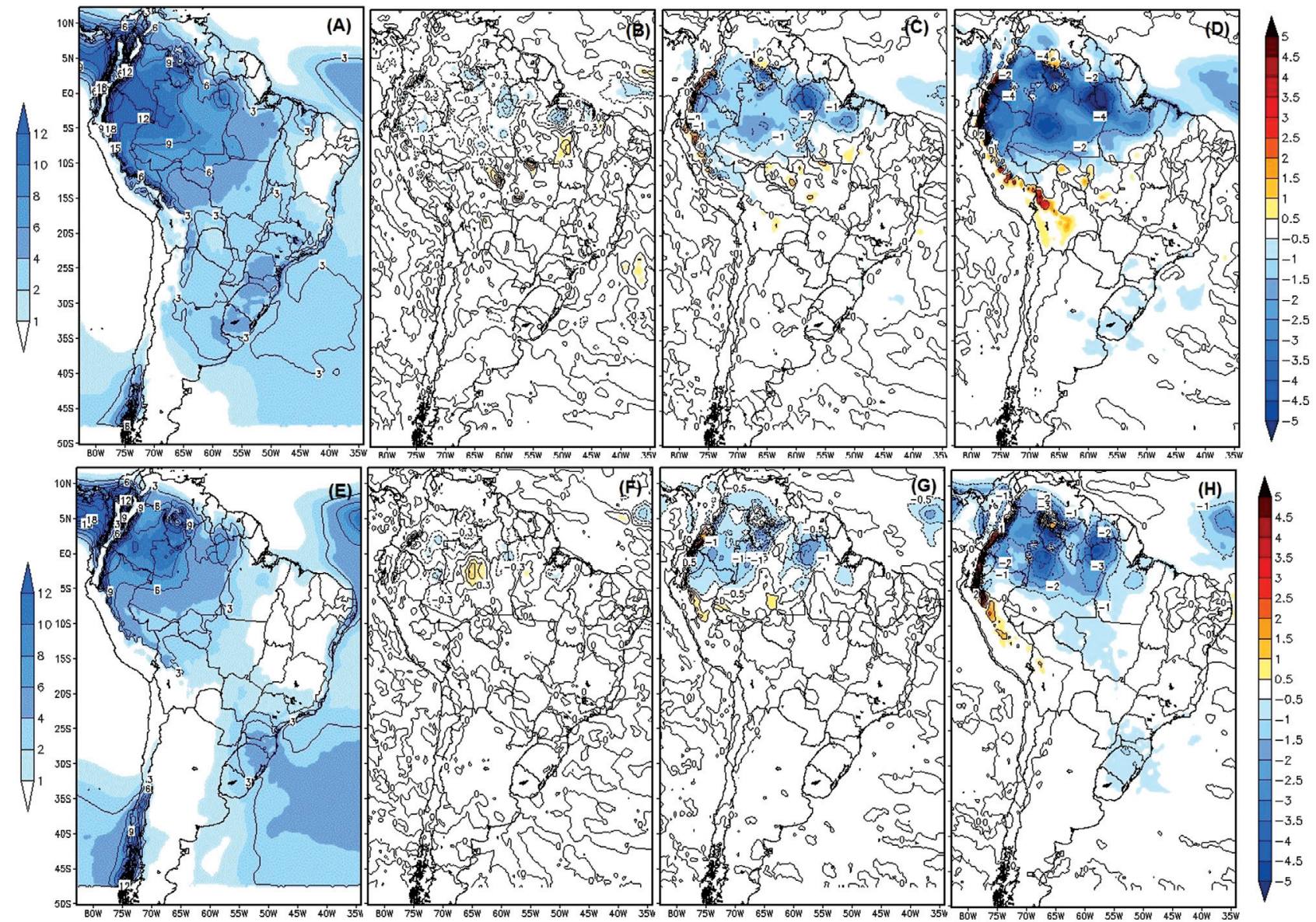

Figura 8 - Impactos na precipitação $\left(\mathrm{mm} \mathrm{dia}^{-1}\right)$ decorrentes dos cenários de mudanças nos usos da terra para as estações úmida e seca. Verão: (A) Distribuição da precipitação para o cenário CNTRL; (B) Impactos na precipitação decorrentes do cenário 2010 em relação ao CNTRL; (C) Impactos na precipitação decorrentes do cenário 2050 em relação ao CNTRL; (D) Impactos na precipitação decorrentes do cenário 2100 em relação ao CNTRL. Inverno: (E) Distribuição de precipitação para o cenário CNTRL; (F) Impactos na precipitação decorrentes do cenário 2010 em relação ao CNTRL; (G) Impactos na precipitação decorrentes do cenário 2050 em relação ao CNTRL; (H) Impactos na precipitação decorrentes do cenário 2100 em relação ao CNTRL.

por sua vez, tende a se desintensificar-se de leste para oeste. Na média, a reciclagem de precipitação na bacia amazônica foi da ordem de $20 \%$, mostrando que, do total de precipitação na bacia, aproximadamente $20 \%$ é decorrente do processo de evapotranspiração local. Esses valores de reciclagem na bacia estão próximos daqueles observados na literatura (Trenberth, 1999; Brubaker, 1993; Nobrega et al., 2005), mostrando que o modelo regional consegue representar bem esse mecanismo na bacia amazônica.

\section{a) Período Úmido}

Nesse período as mudanças decorrentes do desflorestamento foram mais intensas nos cenários de 2050 e 2100 , enquanto que em 2010 poucas mudanças foram observadas (Fig. 10). Pequenas reduções no Pará, Mato Grosso e Rondônia, posicionadas na região de maior taxa de desflorestamento, foram observadas para o ano de 2010. Entretanto, essa redução na reciclagem não foi intensa suficiente para afetar o regime de precipitação na região, conforme observado na Fig. 8. Nessa estação a reciclagem de precipitação apresentou reduções da ordem de $8 \%$ e $22 \%$ para os cená- rios de 2050 e 2100, respectivamente. Em ambos cenários, essas mudanças são explicadas exclusivamente pela redução na evapotranspiração, uma vez que, observaram-se redução na precipitação total e no transporte de umidade (Tabela 2).

\section{b) Período Seco}

Semelhante ao período úmido as mudanças decorrentes do desflorestamento foram mais intensas nos cenários de 2050 e 2100 , enquanto que em 2010 poucas mudanças foram observadas. Nos cenários de 2050 e 2100 observaram-se reduções na maior parte da bacia amazônica, com impactos negativos tornando-se mais intensos à medida que se aumenta o grau do desflorestamento, principalmente durante a estação seca. Isso mostra novamente que as mudanças no uso e cobertura da terra na Amazônia podem modificar os componentes do balanço de água e, principalmente, a reciclagem de precipitação. $\mathrm{Na}$ estação seca a reciclagem de precipitação apresentou reduções da ordem de $12 \%$ e $32 \%$ para os cenários de 2050 e 2100 , respectivamente. Tambem nesse período as mudanças são 
Tabela 2 - Componentes do balanço de água e reciclagem de precipitação simulados pelo modelo regional ETA para os quatros cenários de mudanças no uso da terra na Amazônia: CNTRL, 2010, 2050 e 2100 para a média anual, período úmido e período seco para bacia amazônica. P - precipitação $\left(\mathrm{mm} \cdot \mathrm{dia}^{-1}\right) ; \mathrm{E}$ - evapotranspiração $\left(\mathrm{mm} \cdot \mathrm{dia}^{-1}\right) ; \mathrm{C}$ - convergência de umidade $\left(\mathrm{mm} \cdot \mathrm{dia}^{-1}\right) ; \mathrm{F}$ - fluxo de umidade $\left(\mathrm{kg} \mathrm{m}^{-1} \cdot \mathrm{s}^{-1}\right) ; \mathrm{R}$ - escoamento superficial $\left(\mathrm{mm} \cdot \mathrm{dia}^{-1}\right)$; REC - reciclagem de precipitação (\%).

\begin{tabular}{|c|c|c|c|c|c|c|c|}
\hline \multicolumn{8}{|c|}{ Bacia Amazônica } \\
\hline \multicolumn{8}{|c|}{ Anual } \\
\hline & CNTRL & 2010-CNTRL & 2010-CNTRL(\%) & 2050-CNTRL & 2050-CNTRL(\%) & DESM-CNTRL & DESM-CNTRL(\%) \\
\hline $\mathrm{P}$ & 4,6 & $-0,1$ & 2,1 & $-0,6$ & 13,0 & $-1,6$ & 34,8 \\
\hline E & 3,0 & $-0,1$ & 3,3 & $-0,4$ & 13,3 & $-1,1$ & 36,7 \\
\hline $\mathrm{C}$ & 1,4 & 0,0 & 0,0 & 0,1 & 7,1 & 0,2 & 14,3 \\
\hline $\mathrm{F}$ & 201,7 & $-1,6$ & 0,8 & $-3,5$ & 1,7 & $-1,9$ & 0,9 \\
\hline $\mathrm{R}$ & 1,6 & $-0,1$ & 6,2 & $-0,2$ & 12,5 & $-0,5$ & 31,2 \\
\hline REC & 18,3 & $-0,4$ & 2,2 & $-1,7$ & 9,3 & $-5,4$ & 29,5 \\
\hline \multicolumn{8}{|c|}{ Período úmido } \\
\hline & CNTRL & 2010-CNTRL & 2010-CNTRL(\%) & 2050-CNTRL & 2050-CNTRL(\%) & DESM-CNTRL & DESM-CNTRL(\%) \\
\hline $\mathrm{P}$ & 5,9 & $-0,1$ & 1,7 & $-0,7$ & 11,9 & $-1,7$ & 28,8 \\
\hline E & 3,4 & $-0,1$ & 2,9 & $-0,3$ & 8,8 & $-1,0$ & 29,4 \\
\hline $\mathrm{C}$ & 2,0 & 0,0 & 0,0 & 0,0 & 0,0 & 0,0 & 0,0 \\
\hline $\mathrm{F}$ & 218,0 & $-2,0$ & 0,9 & $-4,5$ & 2,1 & $-4,5$ & 2,1 \\
\hline $\mathrm{R}$ & 2,5 & 0,0 & 0,0 & $-0,3$ & 12,0 & $-0,8$ & 32,0 \\
\hline REC & 19,1 & $-0,4$ & 2,1 & $-1,5$ & 7,8 & $-4,2$ & 21,9 \\
\hline \multicolumn{8}{|c|}{ Período seco } \\
\hline & CNTRL & 2010-CNTRL & 2010-CNTRL(\%) & 2050-CNTRL & 2050-CNTRL(\%) & DESM-CNTRL & DESM-CNTRL(\%) \\
\hline $\mathrm{P}$ & 3,6 & $-0,1$ & 2,7 & $-0,3$ & 8,3 & $-1,1$ & 30,5 \\
\hline E & 2,7 & 0,0 & 0,0 & $-0,3$ & 11,1 & $-1,0$ & 37,0 \\
\hline $\mathrm{C}$ & 0,9 & 0,1 & 11,1 & 0,3 & 33,3 & 0,5 & 55,5 \\
\hline $\mathrm{F}$ & 200,0 & $-1,2$ & 0,6 & $-2,8$ & 1,4 & $-1,4$ & 0,7 \\
\hline $\mathrm{R}$ & 0,8 & 0,1 & 12,5 & 0,1 & 12,5 & 0,0 & 0,0 \\
\hline REC & 17,0 & $-0,5$ & 2,9 & $-2,0$ & 11,8 & $-5,6$ & 32,9 \\
\hline
\end{tabular}

explicadas exclusivamente pela redução na evapotranspiração, uma vez que, observaram-se redução na precipitação total e no transporte de umidade. Sazonalmente, as mudanças na reciclagem de precipitação foram mais intensas durante a estação seca, sendo também a redução na evapotranspiração o mecanismo dominante na redução na reciclagem. Nessa estação, as reduções mais intensas na porção sul-sudeste da bacia amazônica mostra que os impactos na reciclagem de precipitação são sempre maiores na região onde o papel da evapotranspiração é preponderante. Assim sendo, o efeito do desflorestamento sobre a reciclagem é mais significativo nas regiões onde fluxo de vapor dágua é pequeno e onde a evapotranspiração tem mais influência sobre o mecanismo de reciclagem de precipitação. Esses resultados indicam que, à condição de estresse do solo tem papel fundamental no processo de reciclagem de precipitação, e com o desflorestamento, seus efeitos são amplificados.

Por meio da estimativa de reciclagem de precipitação calculou-se a precipitação de origem advectada e local, e também seus respectivos impactos referentes aos cenários de desflorestamento. A precipitação local é aquela gerada a partir da evapotranspiração na região, enquanto a precipitação advectada é aquela oriunda do transporte de umidade proveniente de outras regiões. Nos cenários de $2050 \mathrm{e}$ 2100 , a redução na precipitação total sobre a bacia amazônica foi determinada tanto por reduções na precipitação local (33\% para 2050 e 32\% para 2100) quanto reduções na de origem advectada, sendo que, a redução da precipitação advectada (67\% para 2050 e $68 \%$ para 2100$)$ teve papel preponderante. Isso indica que o desflorestamento pode modificar a precipitação total através das alterações na precipitação de origem local, por meio do mecanismo de reciclagem de precipitação e evapotranspiração, e naquela de origem advectada, devido às mudanças no transporte $\mathrm{e}$ convergência de umidade na região. Esses resultados mostram que o desflorestamento pode conduzir a mudanças na circulação em escalas local e regional e, consequentemente, no transporte e convergência de umidade, e finalmente, alterando o regime de precipitação sobre a região. 

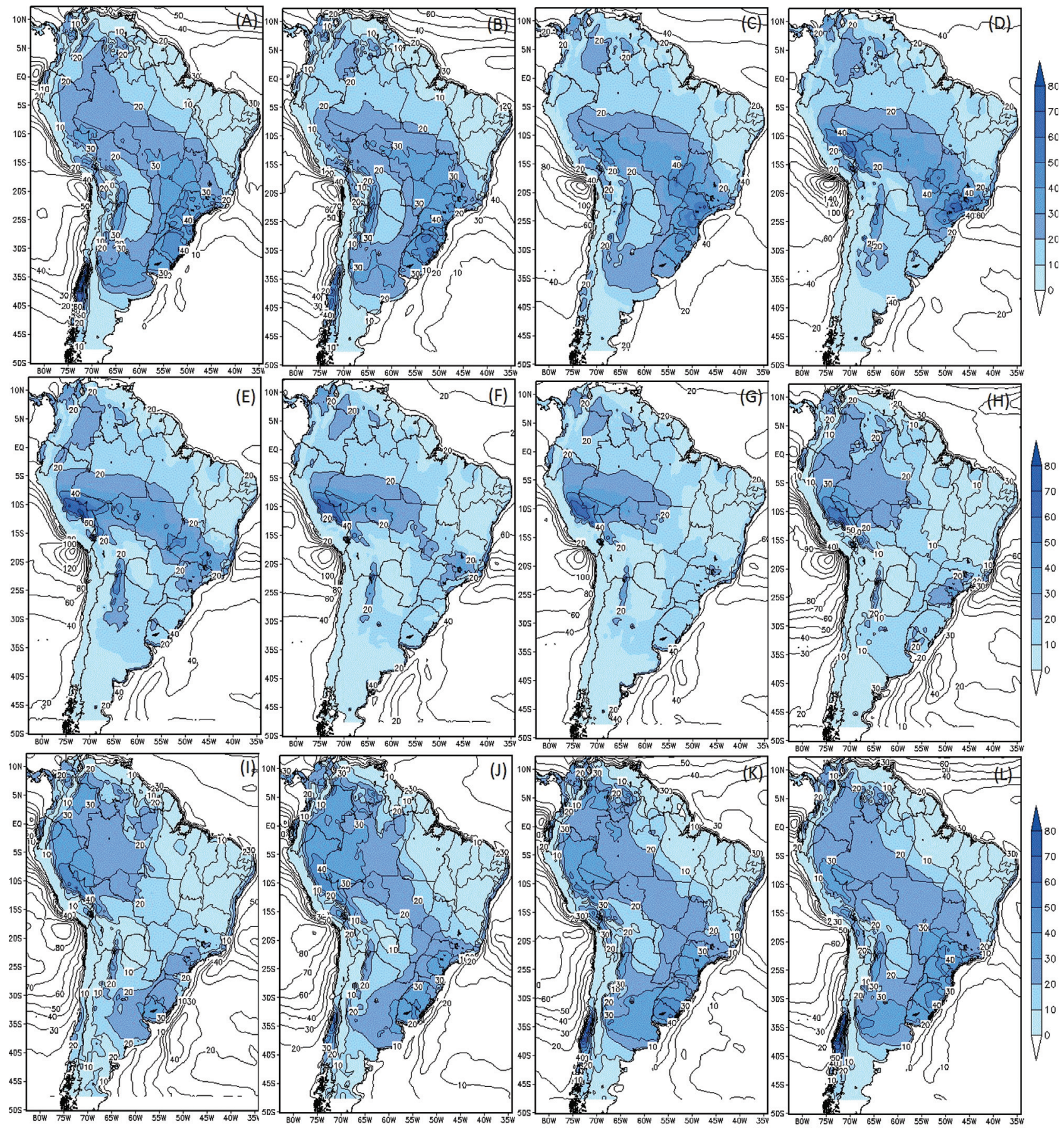

Figura 9 - Distribuição sazonal da reciclagem de precipitação (\%) para o experimento controle: (A) Janeiro; (B) Fevereiro; (C) Março; (D) Abril; (E) Maio; (F) Junho; (G) Julho; (H) Agosto; (I) Setembro; (J) Outubro; (K) Novembro; (L) Dezembro.

\section{Conclusões}

O objetivo principal desse estudo foi avaliar o papel das mudanças nos usos e cobertura da terra (desflorestamento) na reciclagem de precipitação na bacia amazônica utilizando cenários de desflorestamento referentes ao estado atual e projeções para situações futuras. Em todos os cenários de desflorestamento observou-se aumento na temperatura do ar devido à redução na evapotranspiração e no comprimento de rugosidade da superfície. A reciclagem de precipitação aumentou de sudeste para norte-noroeste sobre a bacia, com valores variando entre $20 \%$ a $40 \%$; estando diretamente relacionada à intensificação no transporte de umidade no sentido leste-oeste. As mudanças significativas na reciclagem de precipitação, decorrentes do desflorestamento, ocorreram nos cenários de 2050 e 2100 , enquanto que para a situação atual, as mudanças não foram intensas 

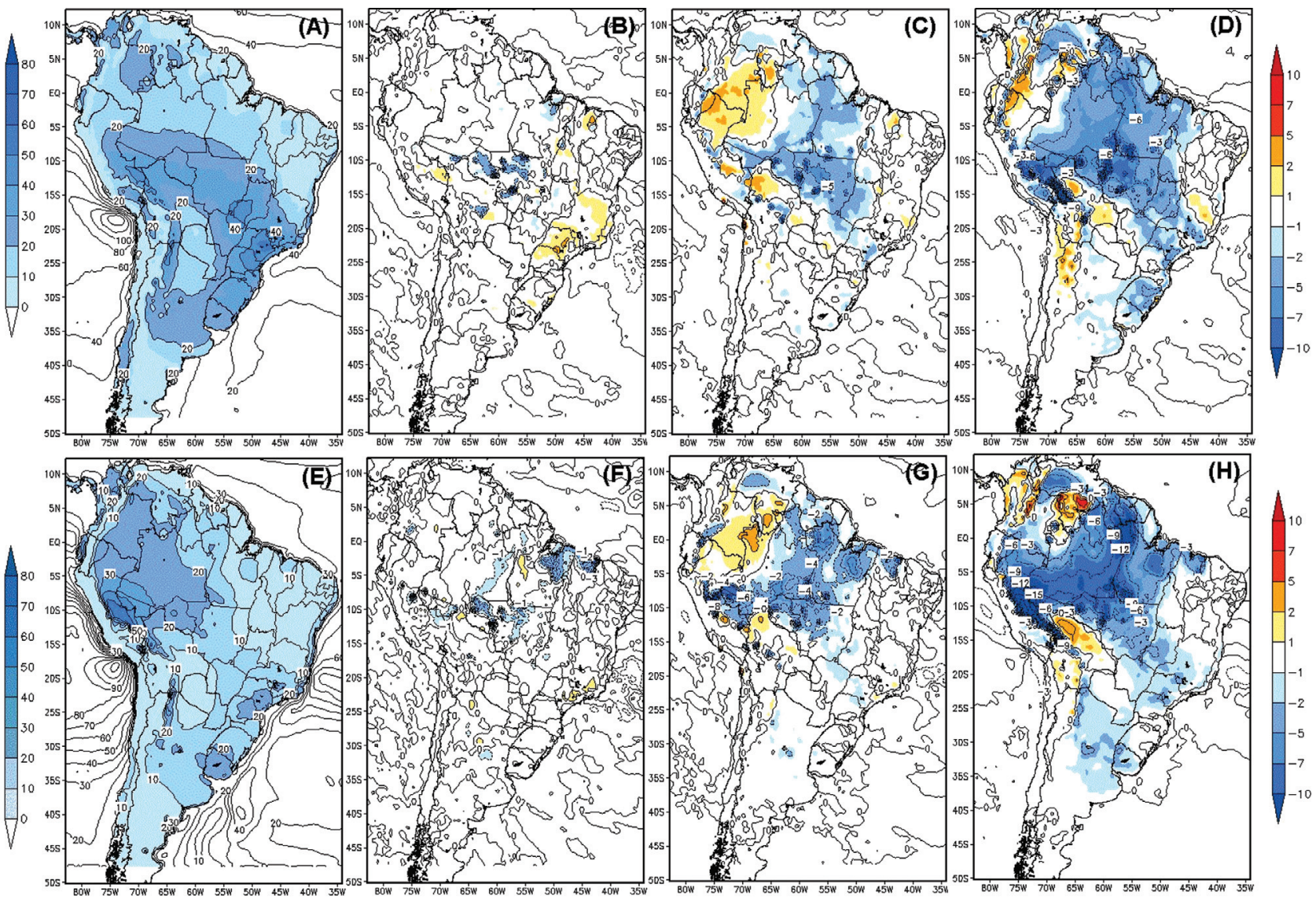

Figura 10 - Impactos na reciclagem de precipitação (\%) decorrentes dos cenários de mudanças nos usos da terra para as estações úmida e seca. Verão: (A) Distribuição da reciclagem de precipitação para o cenário CNTRL; (B) Impactos na reciclagem de precipitação decorrentes do cenário 2010 em relação ao CNTRL; (C) Impactos na reciclagem de precipitação decorrentes do cenário 2050 em relação ao CNTRL; (D) Impactos na reciclagem de precipitação decorrentes do cenário 2100 em relação ao CNTRL. Inverno: (E) Distribuição da reciclagem de precipitação para o cenário CNTRL; (F) Impactos na reciclagem de precipitação decorrentes do cenário 2010 em relação ao CNTRL; (G) Impactos na reciclagem de precipitação decorrentes do cenário 2050 em relação ao CNTRL; (H) Impactos na reciclagem de precipitação decorrentes do cenário 2100 em relação ao CNTRL.

suficientes para afetar o regime de precipitação na bacia. A reciclagem de precipitação apresentou reduções da ordem de $9 \%$ e $30 \%$ para os cenários de 2050 e 2100 , respectivamente. Essas mudanças foram explicadas pela redução na evapotranspiração, uma vez que, a precipitação total e o transporte de umidade apresentaram reduções. Sazonalmente, as mudanças na reciclagem de precipitação foram mais intensas durante a estação seca, e na porção sulsudeste da bacia amazônica, mostrando que, os impactos na reciclagem são sempre maiores na região onde o papel da evapotranspiração é preponderante para a reciclagem. $\mathrm{O}$ efeito do desflorestamento sobre a reciclagem é mais significativo nas regiões onde fluxo de vapor d'água é pequeno e onde a evapotranspiração tem mais influência sobre o mecanismo de reciclagem de precipitação. Nos cenários futuros, a redução na precipitação total sobre a bacia amazônica foi determinada tanto por reduções na precipitação de origem local (33\%) quanto na de origem advectada, sendo que, a redução da precipitação advectada teve papel preponderante $(68 \%)$. Isso indica que o desflorestamento pode modificar a precipitação total através das alterações na precipitação de origem local, por meio do mecanismo de reciclagem de precipitação e evapotranspiração, e naquela de origem advectada, devido às mudanças no transporte $\mathrm{e}$ convergência de umidade na região. Diante desses resultados, pode-se observar que até certo ponto a magnitude do desflorestamento pode não conduzir a mudanças significativas na precipitação em escala regional, entretanto, esse panorama não permanecerá se a degradação antropogênica continuar a expandir como vem acorrendo nas últimas décadas na Amazônia. Se as atividades antropogênicas não permitirem que haja a regeneração ambiental, devido às mudanças nos usos da terra, isso pode afetar o equilíbrio clima-vegetação conduzindo a uma condição mais quente e seca, e possivelmente, a um período seco mais longo. Isso, por sua vez, conduziria a graves consequências ecológicas; entre outros efeitos ao aumento na frequência e intensidade do fogo em áreas de florestas. Portanto, a completa e rápida destruição da floresta pode tornar-se um processo irreversível e as mudanças no ciclo hidrológico regional e as perturbações na complexa relação solo-planta-atmosfera 
seriam tão significativas, que a floresta não reestabeleceria por si só, uma vez que a mesma fosse destruída.

\section{Agradecimentos}

Este artigo é parte da Dissertação de Mestrado do Programa de Pós-Graduação em Clima e Ambiente (CLIAMB). O primeiro autor agradece à Coordenação de Aperfeiçoamento de Pessoal de Nível Superior - CAPES pela concessão da bolsa de estudo.

\section{Referências}

ARRAUT, J.M.; SATYAMURTY, P. Precipitation and water vapor transport in the Southern Hemisphere with emphasis on the South American region. Journal of Applied Meteorology and Climatology, v. 48, n. 9, p. 1902-1912, 2009.

BECK, C.; GRIESER, J.; RUDOLF, B.; SCHNEIDER, U. A new monthly precipitation climatology for the global land areas for the period 1951 to 2000. In: Geophys. Res. Abstr., v. 7, p. 07154, 2005.

BRUBAKER, K.L.; ENTEKHABI, D.; EAGLESON, P.S. Estimation of Continental Precipitation Recycling. Journal of Climate, v. 6, n. 6, p. 1077-1089, 1993.

BETTS, A.K. AND M.J. MILLER. A new convective adjustment scheme. Part II: Single column tests using GATE-wave, BOMEX, ATEX, and Arctic Airmass data sets. Quarterly Journal of the Royal Meteorological Society, v. 112, p. 693-710, 1986.

BLACK, T.L. The New NMC Mesoscale Eta Model: Description and Forecast Examples. In: Weather and Forecasting, v. 9, n. 2, p. 265-278, 1994.

BRUBAKER, K.; ENTERKHABI, D.; EAGLESON, P. Estimation of Continental Precipitation Recycling. In: Journal of Climate, v. 6, n. 6, p. 1077-1089, 1993.

CHOU, S.C.; BUSTAMANTE, J.F.; GOMES, J.L. Evaluation of Eta Model seasonal precipitation forecasts over South America. Nonlinear Processes in Geophysics, v. 12, n. 4, p. 537-555, 2005.

CHOU, S.C.; MARENGO, J.A.; LYRA, A.A.; SUEIRO, G.; PESQUERO, J.F., et al. Downscaling of South America present climate driven by 4-member HadCM3 runs. In: Climate Dynamics, v. 38, n. 3-4, p. 635-653, 2012.

CORREIA, F.W.S.; MANZI, A.O.; CÂNDIDO, L.A.; dos SANTOS, R.M.N; PAULIQUEVIS, T. Balanço de umidade na Amazônia e sua sensibilidade às mudanças na cobertura vegetal. Ciência e Cultura, v. 59, n. 3, p. 39-43, 2007.

COSTA, M.H.; FOLEY, J.A. Combined effects of deforestation and doubled atmospheric $\mathrm{CO} 2$ concentrations on the climate of Amazonia. Journal of Climate, v. 13, p. 18-34, 2000.

COX, P.M.; BETTS, R.A.; COLLINS, M.; HARRIS, P.P.; HUNTINGFORD, C. et al. Amazonian Forest die back under climate-carbon cycle projections for the 21 st century. Theoretical and Applied Climatology, v.78. n. 1-3. p. 137-156. 2004.

DEE, D.P.; UPPALA, S.M.; SIMMONS, A.J.; BERRISFORD, P.; POLI, P. et al. The ERA-Interim reanalysis: configuration and performance of the data assimilation system. Quarterly Journal of the Royal Meteorological Society, v. 137, n. 656, p. 553-597, 2011.
EK, M.B.; MITCHELL, K.E.; LIN, Y.; ROGERS, E.; GRUMMEN, P. et al. Implementation of NOAH land surfasse advances in the National Centers for Environmental Prediction operational mesoscale Eta Model. In: Journal of Geophysical Research: Atmospheres, v. 108, n. D22, 2003.

FEARNSIDE, P.M. Deforestation in Brazilian Amazonia: History, Rates, and Consequences. Conservation Biology, v. 19, n. 3, p. 680-688, 2005.

FELS, S.B.; SCHWARZKOPF, M.D. The simplified exchange approximation: a new method for radiative transfer calculations. In: Journal of the Atmospheric Sciences, v. 32, n. 7, p. 1475-1488, 1975.

FREITAS, S.R. Numerical Modeling of the transport and emissions from biomass burning on South America tropical forest and savanna. Numerical Modeling of the transport and emissions from biomass burning on South America tropical forest and savanna, 1999.

GANDU, A.W.; COHEN, J.C.P.; DE SOUZA, J.R.S. Simulation of deforestation in eastern Amazonia using a high-resolution model. Theoretical and Applied Climatology, v. 78, n. 1, p. 123-135, 2004.

GRACE, J.; MALHI, Y.; LLOYD, J. The use of eddy covariance to infer the net carbon dioxide uptake of Brazilian rain forest. In: Global Change Biology, v. 2, n. 3, p. 209-217, 1996.

INPE. Instituto Nacional de Pesquisas Espaciais. Monitoring the Brazilian Amazon forest by satellite: 2015. São José dos Campos, Brazil, 2015.

LACIS, A.A.; HANSEN, J.E. A parameterization of the absorption of solar radiation in earth's atmosphere. In: Journal of the Atmospheric Sciences, v. 31, n. 1, p. 118-133, 1974.

MALHI, Y.; NOBRE, D.; GRACE, J.; KRUIJT, B.; PEREIRA, M. et al. Carbon dioxide transfer over a Central Amazonian rain forest. In: Journal of Geophysical Research, v. 103, p. 31593-31612, 1998.

MARENGO, J.A. Characteristics and spatio-temporal variability of the Amazon River Basin Water Budget. Climate Dynamics, v. 24, n. 1, p. 11-22, 2005.

MARENGO, J.A. Mudanças climáticas globais e seus efeitos sobre a biodiversidade: caracterização do clima atual e definição das alterações climáticas para o território brasileiro ao longo do século XXI. Brasília: MMA, 212 p. 2006a.

MARENGO, J.A. On the Hydrological Cycle of the Amazon Basin: A historical review and current State-of-the-art. In: Revista Brasileira de Meteorologia, v. 21, n. 3a, p. 1-19, 2006b.

MARENGO, J.A.; ESPINOZA, J.C. Extreme seasonal droughts and floods in Amazonia: causes, trends and impacts. International Journal of Climatology, v. 36, p. 1033-1050. 2015.

MELLOR, G.L.; YAMADA, T. A hierarchy of turbulence closure models for boundary layers. Journal of the Atmospheric Sciences, v. 31, n. 7, p. 1791-1806, 1974.

MESINGER, F.; JANJIC, Z.; NICKOVIC, S.; GAVRILOV, D.; DEAVEN, D. The step-mountain coordinate: Model description description and performance for cases of Alpine lee cyclogenesis and for a case of Appalachian redevelopment. Monthly Weather Review, v. 116, n. 7, p. 14931518,1988

MIRANDA, A. C. et al. Fluxes of carbon, water and energy over Brazilian cerrado: an analysis using eddy covariance and 
stable isotopes. Plant, Cell \& Environment, v. 20, n. 3, p. 315-328, 1997.

NEW, M.; HULME M.; JONES, P. Representing twentieth-century space-time climate variability. Part II: Development of 1901-1996 monthly grids of terrestrial surface climate. Journal of Climate, v. 13, n. 13, p. 2217-2238, 2000.

NOBRE, C.A.; MARENGO, J.A.; ARTAXO, P. NOBRE. Understanding the climate of Amazonia: Progress from LBA. Amazonia and Global Change, p. 145-147, 2009.

NÓBREGA, R.S.; CAVALCANTI, E.P.; SOUZA, E.P.Reciclagem de vapor d'água sobre a América do Sul utilizando reanálises do NCEP-NCAR. Revista Brasileira de Meteorologia, v. 20, n. 2, p. 253-262, 2005.

OYAMA, M; NOBRE, C. A new climate-vegetation equilibrium state for Tropical South America. Geophysical Research Letters, v. 30, p. 1-4, 2003.

ROCHA, V.M.; CORREIA, F.W.S.; SATYAMURTY, P.; FREITAS, S; MOREIRA, D. et al. Impacts of land cover and greenhouse gas (GHG) concentration changes on the hydrological cycle in amazon basin: a regional climate model study. Revista Brasileira de Climatologia, v. 15, p. 7-27, 2015.

SALAZAR, L.; NOBRE, C.; OYAMA, M. Climate change consequences on the biome distribuition in tropical South America. Geophysical Research Letters, v. 34, p. 1-6, 2007.

SAMPAIO, G.; NOBRE, C.; COSTA, M. H.; SATYAMURTY, P.; SOARES-FILHO, B. S.; CARDOSO, M. F. Regional climate change over eastern Amazonia caused by pasture and soybean cropland expansion. In: Geophysical Research Letters, v. 34, p. 1-7, 2007.

SATYAMURTY, P.; da COSTA, C.P.W.; MANZI, A.O. Moisture source for the Amazon Basin: a study of contrasting years. Theoretical and Applied Climatology, v. 111, n. 1-2, p. 195-209, 2013.

SESTINI, M.F.; ALVALÁ, R.C.S.; MELLO, E.M.K.; VALERIANO, D.M.; CHOU, S.C.; NOBRE, C.A.; PAIVA, J.A.C.; REIMER, E.S. Elaboração de mapas de vegetação para utilização em modelos meteorológicos e hidrológicos. Instituto Nacional de Pesquisas Espaciais (INPE), São José dos Campos, SP, Brasil, 74pp, 2002.

DIAS, M. A. F. S.; REGNIER, P. Simulation of meso-scale circulations in a deforested area of Rondonia in the dry season. In: GASH, J.H.C.; NOBRE, C.A.; ROBERTS, J.M.; VICTORIA, R.L. (Eds.) Amazonian Deforestation and Climate. New York: J. M. Wiley and Sons, p. 531-547, 1996.

SOARES-FILHO, B. S.; ALENCAR, A.; NEPSTAD, D.; CERQUEIRA, G.; DIAZ, M.; RIVERO, S.; SOLÓRZANOS, L.; VOLL, E. Simulating the response of land-cover change to road paving and governance along a major Amazon highway: the Santarém-Cuiabá corridor. In: Global Change Biology, v. 10, p. 745-764, 2004.
SUD, C.; FENNESSY, M. Influence of evaporation in semi-arid on the July circulation: a numerical study. Journal of Climatology, v. 4, p. 383-398, 1984.

TRENBERTH, K.E. Atmospheric Moisture Recycling: Role of Advection and Local Evaporation. Journal of Climate, v. 12, n. 5 , p. $1368-1381,1999$.

VERA, C.; BAEZ, J.; DOUGLAS, M.; EMANUEL, C.B.; ORSINI, J.A.M.; MEITIN, J.; NICOLINI, M.; NOGUESPAEGLES, J.; PAEGLE, J.; PENALBA, O.; SALIO, P.; SAULO, C.; SILVA DIAS, M.A.F.; SILVA DIAS, P.; ZIPSER, E. The South American Low Level Jet Experiment. Bulletin of the American Meteorological Society, v. 87, n. 1, p. 63-77, 2006.

VILA, D.A.; DE GONCALVES, L.G.G.; TOLL, D.L.; ROZANTE, J.R. Statistical evaluation of combined daily gauge observations and rainfall satellite estimates over continental South America. Journal of Hydrometeorology, v. 10, n. 2, p. 533-543, 2009.

VON RANDOW, C.; ZERI, M.; RESTREPO-COUPE, N.; MUZA, M.N.; DE GONÇALVES, L.G.G.; COSTA, M.H.; ARAIN, M.A. et al. Inter-annual variability of carbon and water fluxes in Amazonian forest, Cerrado and pasture sites, as simulated by terrestrial biosphere models. Agricultura land Forest Meteorology, v. 182, p. 145-155, 2013.

VOLDOIRE, A.; ROYER, J.F. Tropical deforestation and climate variability. Climate Dynamics, v. 22, p. 857-874, 2004.

WRIGHT, I.R.; GASH, J.H.C.; ROCHA, H.R.; ROBERTS, J.M. Modeling surface conductance for Amazonian pasture and forest. In: GASH, J.H.C.; NOBRE, C.A.; ROBERTS, J.M.; VICTORIA, R.L. Amazonian Deforestation and Climate. John Wiley and Sons, 1st ed., p. 437-458, 1996.

XIE, P.; ARKIN, P.A. Global precipitation: a 17 -year monthly analysis based on gauge observations, satellite estimates, and numerical model outputs. Bulletin of the American Meteorological Society, v. 78, n. 11, p. 2539-2558, 1997.

XIE, P.; JANOWIAK, J.E.; ARKIN, P.A.; ADLER, R.; GRUBER, A.; FERRARO, R.; HUFFMAN, G.J.; CURTIS, S. GPCP pentad precipitation analyses: an experimental data set based on gauge observations and satellite estimates. Jornal of Climate, v. 16, n. 13, p. 2197-2214, 2003.

ZHAO, Q.; BLACK, T.L.; BALDWIN, M.E. Implementation of the cloud prediction scheme in the Eta Model at NCEP. In: Weather and Forecasting, v. 12, n. 3, p. 697-712, 1997.

ZHANG, K.; CASTANHO, A.D.A.; GALBRAITH, D.R.; MOGHIM, S.; LEVINE, N.M.; BRAS, R.L.; COE, M.T.; COSTA, M.H.; MALHI, Y.; LONGO, M.; KNOX, R.G.; MCKNIGHT, S.; WANG, J.; MOORCROFT, P.R. The fate of Amazonian ecosystems over the coming century arising from changes in climate, atmospheric $\mathrm{CO} 2$, and land use. Global Change Biology, v. 21, n.7, p. 1-19, 2015.

This is an Open Access article distributed under the terms of the Creative Commons Attribution Non-Commercial License which permits unrestricted non-commercial use, distribution, and reproduction in any medium provided the original work is properly cited. 